\title{
ANÁLISE DA ALIMENTAÇÃO OFERECIDA PARA CRIANÇAS EM UMA CRECHE MUNICIPAL DO RIO GRANDE DO SUL
}

\section{ANALYSIS OF FOOD OFFERED TO CHILDREN IN A PUBLIC DAY CARE OF RIO GRANDE DO SUL}

\author{
Aline Sobreira Bezerra, ${ }^{1}$ Fernanda Bona Coradi. ${ }^{1}$ \\ ${ }^{1}$ Universidade Federal de Santa Maria/Palmeiras das Missões/Brasil. \\ Autor correspondente: Aline Sobreira Bezerra \\ e-mail: alinecelo@hotmail.com
}

\section{EDITORES}

Thiago Gomes Heck

(Unijuí-Brasil)

Adriane Cristina Bernat Kolankiewicz

(Unijuí-Brasil)

\section{EDITORES DE ÁREA}

Educação \& Saúde

Eva Teresinha de Oliveira Boff

(Unijuí-Brasil)

Fisioterapia \& Saúde

Eliane Roseli Winkelmann

(Unijuí-Brasil)

Ciências Farmacêuticas \& Saúde

Marilei Uecker Pletsch

(Unijuí-Brasil)

Nutrição \& Saúde

Lígia Beatriz Bento Franz

(Unijuí-Brasil)

Nadia Oliveira

(Unipampa-Brasil)

Ingrid Perry

(UNESC-Brasil)

Enfermagem e suas contribuições para a prática

Adriane Cristina Kolankiewicz

(Unijuí-Brasil)

Crhis de Brum

(UFFS-Brasil)

Neila de Souza

(UFSM-Brasil)

Exercício Físico \& Saúde

Thiago Gomes Heck

(Unijuí-Brasil)

Anderson Zampier Ulbrich

(UFPR)

Editora Unijuí

Universidade Regional do Noroeste do

Estado do Rio Grande do Sul (Unijuí)

\section{RESUMO}

Este estudo teve como objetivo avaliar as refeições servidas às crianças de 7 meses a 5 anos de idade, matriculadas em uma creche municipal da cidade de Arvorezinha no Estado do Rio Grande do Sul, tendo como foco as necessidades nutricionais de acordo com a faixa etária e o nível de aceitação do cardápio oferecido. Trabalhou-se com o cardápio servido durante a semana e o porcionamento para cada faixa etária. Como referência para avaliar a oferta de nutrientes às crianças, utilizou-se as recomendações de macro e micronutrientes do Fundo Nacional de Desenvolvimento da Educação. Os resultados demonstraram que, para os alunos do berçário, houve deficiência de vitamina A e de sódio, para o maternal houve deficiência de vitamina A e de cálcio e para os pré-escolares houve deficiência na maior parte dos nutrientes ofertados no cardápio, exceto para proteína, vitamina $\mathrm{C}$ e ferro. A inadequação da alimentação oferecida para as crianças pode ser justificada por deficiência no planejamento do cardápio proposto, pela ausência de fichas técnicas e treinamentos para os manipuladores, além da falta de colaboração dos manipuladores em seguir o cardápio proposto e elaborado pelo nutricionista.

Palavras-chave: Alimentação da criança. Alimentação escolar. Planejamento de cardápio. Saúde da criança.

Submetido em: $18 / 7 / 2016$

Aceito em: 6/10/2016 


\section{Revista}

\section{Contexto}

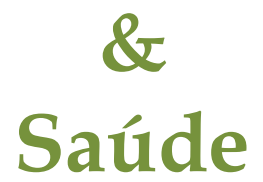

Volume 16

Número 31

2016

ISSN 2176-7114

\begin{abstract}
This study aimed to evaluate the meals served to children from seven months to five years old, enrolled in a municipal nursery of Rio Grande do Sul, focusing on the nutritional needs according to age and the menu level of acceptance offered. Worked with the menu served during the week and portioning for each age group. As a reference to assess the supply of nutrients to children, were used the macro and micronutrient recommendations of the National Education Development Fund. The results showed that for students of nursery was vitamin A deficiency and sodium, for maternal was vitamin A deficiency and calcium and the preschool was deficient in most nutrients offered on the menu, except for protein, vitamin $\mathrm{C}$ and iron. The inadequacy of the food given to the children can be justified by a deficiency in the design of the proposed menu, lack of technical data sheets and training for handlers and the lack of cooperation from handlers to follow the menu proposed and elaborated by nutritionist.
\end{abstract}

Keywords: Nutrition of the child. School feeding. Menu planning. Child health.

\begin{abstract}
A Revista Contexto \& Saúde é um periódico do Departamento de Ciências da Vida da Universidade Regional do Noroeste do Estado do Rio Grande do Sul (Unijuí). É um periódico semestral que tem por objetivo a divulgação da produção técnico-científica de temas relacionados à área de Ciências da Saúde.

O escopo da revista abrange a divulgação de resultados de pesquisa que contemplem avanços no processo saúde-doença-cuidado e no conhecimento e aplicabilidade de novos processos químicos e biológicos em saúde.

Neste periódico, entende-se que a publicação de estudos com os aspectos epidemiológicos, assistenciais e educacionais em saúde, experimentais e aplicados é uma forma a subsidiar e qualificar a atenção à saúde de modo interdisciplinar.
\end{abstract}




\section{INTRODUÇÃO}

O Programa Nacional de Alimentação Escolar (PNAE) é um programa do Ministério da Educação que tem por objetivo complementar a alimentação dos alunos, contribuindo para que estes permaneçam na escola tendo bom desempenho escolar e bons hábitos alimentares (BRASIL, 2009). Segundo a Declaração Universal dos Direitos da Criança (1959) (UNICEF, 1959), a mesma tem o dever de receber estudo gratuito, obrigatório e adequado para torná-la útil para a sociedade, devendo esta e as autoridades públicas empenhar-se em promover estes direitos.

O cardápio da alimentação escolar, perante responsabilidade dos órgãos executores, deve ser programado de modo a suprir, no mínimo, 20\% das necessidades nutricionais diárias (NNDs) dos alunos matriculados na educação infantil turno único. Para as crianças que permanecem na escola em turno integral, a alimentação escolar deve suprir, no mínimo, 70\% das NNDs. O Fundo Nacional de Desenvolvimento da Educação (FNDE) (BRASIL, 2012a) recomenda que as crianças devam receber a quantidade adequada de macro e micronutrientes conforme estabelecido por faixa etária, número de refeições e tempo de permanência na escola.

Para Colares e Freitas (2007), as Unidades de Alimentação e Nutrição (UANs) pertencem ao setor de alimentação coletiva, com o objetivo de gerenciar a produção de refeições nutricionalmente equilibradas, com bom estado higiênico-sanitário para ingesta não domiciliar, que possam ajudar a manter ou recuperar a saúde de coletividades, além de auxiliar na evolução de hábitos alimentares de pessoas que as frequentam.

As recomendações para alimentação de crianças brasileiras menores de dois anos estão simplificadas na publicação dos “Dez Passos para Alimentação Saudável de Crianças Menores de Dois Anos”, para prolongar a duração do aleitamento materno exclusivo, adaptar a alimentação complementar oferecida à criança menor de 2 anos e estimular e fortalecer hábitos alimentares saudáveis (BRASIL, 2010a). A partir dos dois anos é importante apresentar novos alimentos e manter o estímulo à alimentação saudável por meio de alimentos naturais e com baixo consumo de industrializados (SBP, 2006), demonstrando sempre os benefícios de uma boa alimentação. As crianças, aos poucos, vão desenvolvendo a linguagem e a habilidade motora e social, tornandose independentes para escolher seus alimentos, sendo importante oferecer alimentos adequados para educá-las desde cedo a manter bons hábitos alimentares (BRASIL, 2012b).

Sendo assim, este estudo tem por objetivo avaliar parâmetros relacionados aos alimentos e refeições servidas às crianças na faixa etária de 7 meses a 5 anos de idade, matriculadas em uma creche municipal da cidade de Arvorezinha no Estado do Rio Grande do Sul, tendo como foco as necessidades nutricionais de acordo com a faixa etária e o nível de aceitação do cardápio oferecido.

\section{METODOLOGIA}

Estudo transversal sobre o cardápio oferecido na alimentação escolar para os alunos entre sete meses e cinco anos de idade de uma Escola Municipal de Educação Infantil (Emei) do município de Arvorezinha/RS. O cardápio analisado foi ofertado no decorrer de quatro semanas de forma intercalada. As recomendações nutricionais de macro e micronutrientes utilizadas como referência foram as recomendadas pela resolução $\mathrm{n}^{\circ} 38$ de 16 de julho de 2009 do FNDE (BRASIL, 2009).

O projeto foi aprovado pelo Comitê de Ética em Pesquisa da Universidade Federal de Santa Maria/RS, sob o número CAEE 36874614.0.0000.5346. Também foi aprovado pela Secretaria de Educação do município estudado. 


\section{População de estudo}

A cidade de Arvorezinha está localizada no Rio Grande do Sul e tem 10.225 habitantes, valores apurados pelo censo demográfico em 2015 (IBGE, 2016). Até o momento da pesquisa, no ano de 2014, a cidade tinha uma Escola Municipal de Educação Infantil (Emei) que recebia diariamente 120 crianças de 7 meses a 5 anos, considerando que 42 crianças ficavam apenas meio turno na escola, caracterizadas como grupo pré-escolar.

As crianças do berçário e maternal permaneciam em turno integral (7h30min às 17h30min) e conforme observado recebiam cinco refeições diárias, incluindo o desjejum, colação, almoço, lanche da tarde e jantar. Já os alunos da pré-escola recebiam apenas o almoço, e permanecia meio turno (7h30min as $12 \mathrm{~h}$ ) na escola.

O sistema adotado pela creche para distribuição das refeições é do modo convencional, ou seja, os funcionários servem as crianças. $\mathrm{O}$ almoço era servido a partir de 10h30min. As turmas participantes eram do berçário (grupo 1 - 7 meses a 11 meses), maternal (grupo 2 - 1 a 3 anos), que funcionava no período integral de segunda a sexta-feira, e pré-escola (grupo 3 - 4 a 5 anos) do turno da manhã que funciona de segunda a sexta-feira.

\section{Coleta de dados}

Os alunos do maternal e da pré-escola recebiam o mesmo cardápio, enquanto para os do berçário o mesmo era adaptado para a idade. Inicialmente foi solicitado ao nutricionista, responsável pela escola, o cardápio de todas as refeições oferecidas às crianças durante o mês de agosto no ano de 2014 para analisar o porcentual proposto pelo PNAE (BRASIL, 2009, 2012a) e consumido pelas crianças quanto aos teores de carboidrato, proteína, lipídeo, fibra, sódio, vitamina $\mathrm{A}$, vitamina $\mathrm{C}$, cálcio, zinco, ferro e magnésio. Para cálculo do valor nutricional das refeições foi utilizada a Tabela Brasileira de Composição dos Alimentos (2011) e a Tabela para Avaliação de Consumo Alimentar em Medidas Caseiras (PINHEIRO et al., 2008).

Em seguida foi observado durante uma semana o almoço na creche, e avaliado por meio da pesagem do alimento com balança eletrônica digital portátil (Eletronic Kitchen Scale®). Pelo ao pouco tempo disponível das cozinheiras não foi possível quantificar individualmente o alimento que as crianças estavam recebendo, mas somente o peso do prato completo.

O almoço era servido por turma e faixa etária em razão do pequeno espaço disponível. Com isso, foi possível analisar quantas crianças ingeriam todo o alimento e quantas não ingeriam nada. As preparações foram divididas em porções de acordo com o que as crianças habitualmente consumiam, sendo pesados três porções/pratos para obter a quantidade média servida às crianças. As três amostras foram aleatoriamente coletadas no momento da oferta das refeições. Nos casos de repetição foram anotados o tipo e a quantidade do(s) alimento(s) em formulário e acrescidas as porções servidas.

Foi considerado resto todo o alimento que a criança deixasse no prato e o destino final era o lixo, sendo pesadas na mesma balança. Foi considerado sobra limpa todo o alimento que não foi servido, permanecendo nas panelas e que seriam ofertadas no turno da tarde. Para calcular o porcentual de resto ingesta (\% IR) foi utilizada a fórmula proposta por Abreu (SPINELLI; ZANARDI, 2003), dividindo-se o peso da refeição rejeitada pelo peso da refeição distribuída, e transformado o valor em porcentual. Para obter o peso médio dos pratos somou-se o peso de todos eles e dividiu-se pelo número de crianças.

Para se obter o porcentual de sobras foi utilizada a seguinte fórmula: \% de sobras = sobra após a distribuição x 100/peso da refeição produzida. 
A pesquisa foi realizada no turno da manhã e as cozinheiras foram acompanhadas desde o preparo dos alimentos até o final das refeições, iniciando às 8 horas da manhã e finalizando as 11 horas.

\section{Cardápio escolar}

Na Tabela 1 observa-se o cardápio semanal proposto pela nutricionista, e na Tabela 2 o ofertado aos alunos da escola, com algumas modificações pelos manipuladores de alimentos conforme produtos alimentícios disponíveis na creche.

Tabela 1 - Cardápio semanal proposto pela nutricionista. Arvorezinha, RS, 2014

\begin{tabular}{|c|c|c|c|c|c|}
\hline $\begin{array}{c}\text { Dia da } \\
\text { semana }\end{array}$ & $\begin{array}{l}\text { Café da } \\
\text { manhã }\end{array}$ & Colação & Almoço & $\begin{array}{c}\text { Lanche da } \\
\text { tarde }\end{array}$ & $\begin{array}{c}\text { Lanche II } \\
\text { (Jantar) }\end{array}$ \\
\hline $\begin{array}{l}\text { Segunda- } \\
\text { feira }\end{array}$ & $\begin{array}{l}\text { Sopa de } \\
\text { bolacha }\end{array}$ & Banana & $\begin{array}{c}\text { Massa com } \\
\text { carne moída e } \\
\text { cenoura em } \\
\text { palito }\end{array}$ & $\begin{array}{l}\text { Creme de } \\
\text { chocolate }\end{array}$ & $\begin{array}{l}\text { Igual ao } \\
\text { almoço }\end{array}$ \\
\hline $\begin{array}{c}\text { Terça- } \\
\text { feira }\end{array}$ & $\begin{array}{l}\text { Leite com } \\
\text { café e pão } \\
\text { com } \\
\text { presunto e } \\
\text { queijo }\end{array}$ & Laranja & $\begin{array}{c}\text { Arroz e feijão } \\
\text { com carne } \\
\text { moída, } \\
\text { brócolis e } \\
\text { couve-flor }\end{array}$ & $\begin{array}{l}\text { Banana e } \\
\text { maçã }\end{array}$ & $\begin{array}{l}\text { Igual ao } \\
\text { almoço }\end{array}$ \\
\hline $\begin{array}{l}\text { Quarta- } \\
\text { feira }\end{array}$ & $\begin{array}{l}\text { Leite com } \\
\text { café e bolo } \\
\text { de chocolate }\end{array}$ & Mamão & $\begin{array}{c}\text { Sopa de } \\
\text { legumes com } \\
\text { moranga e pão }\end{array}$ & $\begin{array}{c}\text { Bolacha } \\
\text { doce e } \\
\text { salgada com } \\
\text { leite }\end{array}$ & $\begin{array}{l}\text { Igual ao } \\
\text { almoço }\end{array}$ \\
\hline $\begin{array}{l}\text { Quinta- } \\
\text { feira }\end{array}$ & $\begin{array}{c}\text { Batida de } \\
\text { leite com } \\
\text { maçã e } \\
\text { bolacha doce }\end{array}$ & Maçã & $\begin{array}{l}\text { Massa com } \\
\text { carne de } \\
\text { frango e } \\
\text { salada de } \\
\text { tomate e } \\
\text { alface }\end{array}$ & $\begin{array}{l}\text { Pizza de } \\
\text { frango }\end{array}$ & $\begin{array}{l}\text { Igual ao } \\
\text { almoço }\end{array}$ \\
\hline $\begin{array}{l}\text { Sexta- } \\
\text { feira }\end{array}$ & $\begin{array}{l}\text { Leite com } \\
\text { achocolatado } \\
\text { e bolo de } \\
\text { cenoura }\end{array}$ & Abacaxi & $\begin{array}{l}\text { Polenta com } \\
\text { carne moída e } \\
\text { repolho } \\
\text { refogado e } \\
\text { chicória }\end{array}$ & $\begin{array}{l}\text { Batida de } \\
\text { maçã e } \\
\text { bolacha } \\
\text { doce e } \\
\text { salgada }\end{array}$ & $\begin{array}{l}\text { Igual ao } \\
\text { almoço }\end{array}$ \\
\hline
\end{tabular}


Tabela 2 - Cardápio semanal ofertado com modificações. Arvorezinha, RS, 2014

\begin{tabular}{|c|c|c|c|c|c|}
\hline $\begin{array}{c}\text { Dia da } \\
\text { semana }\end{array}$ & $\begin{array}{l}\text { Café da } \\
\text { manhã }\end{array}$ & Colação & Almoço & $\begin{array}{c}\text { Lanche da } \\
\text { tarde }\end{array}$ & $\begin{array}{l}\text { Lanche II } \\
\text { (Jantar) }\end{array}$ \\
\hline $\begin{array}{l}\text { Segunda- } \\
\text { feira }\end{array}$ & $\begin{array}{l}\text { Sopa de } \\
\text { bolacha }\end{array}$ & Banana & $\begin{array}{l}\text { Massa com } \\
\text { carne moída e } \\
\text { cenoura em } \\
\text { palito }\end{array}$ & $\begin{array}{l}\text { Creme de } \\
\text { chocolate }\end{array}$ & $\begin{array}{l}\text { Igual ao } \\
\text { almoço }\end{array}$ \\
\hline $\begin{array}{c}\text { Terça- } \\
\text { feira }\end{array}$ & $\begin{array}{l}\text { Leite com café } \\
\text { e pão com } \\
\text { presunto e } \\
\text { queijo }\end{array}$ & $\begin{array}{l}\text { Bolacha } \\
\text { doce }\end{array}$ & $\begin{array}{l}\text { Arroz e feijão } \\
\text { com carne } \\
\text { moída, brócolis } \\
\text { e couve-flor }\end{array}$ & $\begin{array}{l}\text { Banana e } \\
\text { maçã }\end{array}$ & $\begin{array}{l}\text { Igual ao } \\
\text { almoço }\end{array}$ \\
\hline $\begin{array}{l}\text { Quarta- } \\
\text { feira }\end{array}$ & $\begin{array}{l}\text { Leite com café } \\
\text { e pão com } \\
\text { presunto e } \\
\text { queijo }\end{array}$ & Maçã & $\begin{array}{l}\text { Polenta com } \\
\text { carne de frango, } \\
\text { repolho } \\
\text { refogado, alface } \\
\text { e rúcula }\end{array}$ & $\begin{array}{c}\text { Bolacha } \\
\text { doce e } \\
\text { salgada com } \\
\text { leite }\end{array}$ & $\begin{array}{l}\text { Igual ao } \\
\text { almoço }\end{array}$ \\
\hline $\begin{array}{l}\text { Quinta- } \\
\text { feira }\end{array}$ & $\begin{array}{c}\text { Café com leite, } \\
\text { bolacha doce e } \\
\text { maçã }\end{array}$ & $\begin{array}{l}\text { Bolacha } \\
\text { doce e } \\
\text { salgada }\end{array}$ & $\begin{array}{c}\text { Massa com } \\
\text { carne moída e } \\
\text { salada de } \\
\text { chuchu, alface e } \\
\text { beterraba }\end{array}$ & $\begin{array}{l}\text { Pizza de } \\
\text { frango }\end{array}$ & $\begin{array}{l}\text { Igual ao } \\
\text { almoço }\end{array}$ \\
\hline $\begin{array}{c}\text { Sexta- } \\
\text { feira }\end{array}$ & $\begin{array}{c}\text { Leite com } \\
\text { achocolatado e } \\
\text { bolacha doce }\end{array}$ & Mamão & $\begin{array}{l}\text { Sopa de } \\
\text { legumes com } \\
\text { moranga }\end{array}$ & $\begin{array}{l}\text { Batida de } \\
\text { maçã e } \\
\text { bolacha doce } \\
\text { e salgada }\end{array}$ & $\begin{array}{l}\text { Igual ao } \\
\text { almoço }\end{array}$ \\
\hline
\end{tabular}

As modificações do cardápio ocorriam principalmente nas hortaliças, nas proteínas e alterações de preparações entre os dias ofertados. Cabe ressaltar que, por se tratar de uma instituição pública dependente de verba da prefeitura, governo e licitação, todos os produtos utilizados na composição do cardápio poderiam ser alterados, gerando modificações no mesmo. Além disso, para a aquisição dos gêneros alimentícios para o PNAE é obrigatória a compra de, no mínimo, $30 \%$ da agricultura familiar. Na escola em estudo a compra fica limitada a este padrão.

\section{RESULTADOS}

Na Tabela 3 são descritas as porções da refeição (almoço) por grupo nos diferentes dias avaliados, conforme cardápio da Tabela 2. 
Tabela 3 - Distribuição das refeições (almoço) em porções médias conforme grupo e número de crianças. Arvorezinha, RS, 2014

\begin{tabular}{|c|c|c|c|c|c|}
\hline Dia & & Grupo $1^{1}$ & Grupo $2^{2}$ & Grupo $3^{3}$ & Total \\
\hline \multirow[b]{2}{*}{$\mathbf{1}^{\mathbf{o}}$} & Número de crianças & 8 & 41 & 15 & 64 \\
\hline & Porções médias (g) & 117 & 290 & 100 & - \\
\hline \multirow[b]{2}{*}{$2^{\mathbf{o}}$} & Número de crianças & 8 & 41 & 12 & 61 \\
\hline & Porções médias (g) & 220 & 180 & 240 & - \\
\hline \multirow[b]{2}{*}{$\mathbf{3}^{\mathbf{o}}$} & Número de crianças & 6 & 41 & 12 & 59 \\
\hline & Porções médias & 145 & 180 & 147 & - \\
\hline \multirow[b]{2}{*}{$4^{\circ}$} & Número de crianças & 6 & 40 & 13 & 59 \\
\hline & Porções médias & 100 & 190 & 126 & - \\
\hline \multirow[b]{2}{*}{$\mathbf{5}^{\mathbf{o}}$} & Número de crianças & 7 & 34 & 10 & 51 \\
\hline & Porções médias & 109 & 195 & $40 *$ & - \\
\hline
\end{tabular}

${ }^{1}$ Berçário; ${ }^{2}$ Maternal; ${ }^{3}$ Pré-escola; *Oferta apenas de bolachas doces e salgadas, ou seja, não há comida de sal.

Observou-se que no primeiro dia $25 \%$ das crianças não ingeriram as preparações e $48 \%$ não comeram cenoura, sendo menor a aceitação pelas crianças do maternal. No segundo dia, $11 \%$ das crianças não ingeriram as preparações ofertadas, $24,5 \%$ não ingeriram verduras e hortaliças, mas, em contrapartida, $22 \%$ repetiram as hortaliças.

No terceiro dia todas as crianças ingeriram alguma das preparações, mas $25 \%$ delas não ingeriram verduras e hortaliças. No quarto dia, 13,5\% não ingeriram as preparações, sendo este o dia com maior rejeição alimentar pelas crianças. Em algumas turmas do berçário não houve a oferta de hortaliças, pois as crianças não comiam e havia grande desperdício.

Já no quinto dia de observação, 11,7\% não ingeriram as preparações e 7,8\% não comeram verduras e hortaliças. Neste dia não houve a oferta de bolo no café da manhã e o almoço também não correspondeu ao proposto.

\section{Avaliação da refeição quanto ao destino do alimento}

Quanto à aceitação do cardápio da escola foi possível verificar que, em virtude da repetição rotineira dos alimentos, estes passam a não agradar as crianças. As manipuladoras responsáveis pelo preparo, por não utilizarem medidas caseiras ou outra padronização, destinavam uma grande parte dos alimentos produzidos ao lixo. Na Tabela 4 é possível analisar dados da quantidade de alimento cozido, distribuído, resto com destino ao lixo, sobra dos alimentos que não foram para a distribuição, resto ingesta e número de refeições por dia, ofertado para as crianças do maternal e pré-escola no turno matutino. 
Tabela 4 - Quantidade de alimento produzido, distribuído, resto, sobra, número de refeições ofertadas aos alunos da pré-escola e porcentual de resto ingesta. Arvorezinha, RS, 2014

\begin{tabular}{ccccccc}
\hline Dia & $\begin{array}{c}\text { Alimento } \\
\text { produzido } \\
(\mathbf{k g})\end{array}$ & $\begin{array}{c}\text { Distribuído } \\
(\mathbf{k g})\end{array}$ & $\begin{array}{c}\text { Resto } \\
(\mathbf{k g})\end{array}$ & $\begin{array}{c}\text { Sobra } \\
(\mathbf{k g})\end{array}$ & $\begin{array}{c}\text { Refeições } \\
(\mathbf{n})\end{array}$ & $\begin{array}{c}\text { IR* }^{*} \\
(\mathbf{\%})\end{array}$ \\
\hline $\mathbf{1}$ & 9,45 & 5,50 & 0,90 & 3,95 & 56 & 16,4 \\
\hline $\mathbf{2}$ & 14,00 & 10,00 & 2,2 & 4,00 & 53 & 22,5 \\
\hline $\mathbf{3}$ & 9,80 & 7,00 & 1,90 & 2,80 & 53 & 27,1 \\
\hline $\mathbf{4}$ & 10,00 & 9,00 & 3,00 & 1,00 & 53 & 33,3 \\
\hline $\mathbf{5}$ & 14,24 & 9,00 & 1,50 & 5,24 & 42 & 16,7 \\
\hline TOTAL & $\mathbf{5 7 , 4 9}$ & $\mathbf{4 0 , 5 0}$ & $\mathbf{9 , 5}$ & $\mathbf{1 6 , 9 9}$ & $\mathbf{2 5 7}$ & - \\
\hline
\end{tabular}

*IR: Resto-Ingesta.

Já na Tabela 5 podemos observar as mesmas informações, porém com as refeições ofertadas para as crianças do berçário.

Tabela 5 - Quantidade de alimento produzido, distribuído, resto, sobra e número de refeições, ofertados aos alunos do berçário. Arvorezinha, RS, 2014

\begin{tabular}{lcccccc}
\hline DIA & $\begin{array}{c}\text { ALIMENTO } \\
\text { PRODUZIDO } \\
(\mathbf{k g})\end{array}$ & $\begin{array}{c}\text { DISTRIBUÍDO } \\
(\mathbf{k g})\end{array}$ & RESTO & SOBRA & REFEIÇÕES & IR (\%) \\
\hline $\mathbf{1}^{\circ}$ & 1,50 & 0,936 & 0,200 & 0,564 & 8 & 21,4 \\
\hline $\mathbf{2}^{\circ}$ & 2,00 & 1,768 & 0,106 & 0,232 & 8 & 5,9 \\
\hline $\mathbf{3}^{\circ}$ & 1,20 & 0,900 & 0,200 & 0,300 & 6 & 22,2 \\
\hline $\mathbf{4}^{\circ}$ & 1,09 & 0,720 & 0,206 & 0,370 & 6 & 28,6 \\
\hline $\mathbf{5}^{\circ}$ & 1,00 & 0,750 & 0,166 & 0,250 & 7 & 22,1 \\
\hline TOTAL & $\mathbf{6 , 7 9}$ & $\mathbf{5 , 0 7 4}$ & $\mathbf{0 , 8 7 8}$ & $\mathbf{1 , 7 1 6}$ & $\mathbf{3 5}$ & - \\
\hline
\end{tabular}

Avaliação da refeição ofertada quanto às recomendações do FNDE

As recomendações nutricionais diárias para cada grupo escolar conforme faixa etária propostas pelo FNDE e os valores porcentuais médios ofertados no cardápio avaliado, estão descritos na Tabela 6. 
Tabela 6 - Valores de referência de energia, macro e micronutrientes e valor \% médio da diferença do FNDE, ofertado aos alunos conforme cardápio. Arvorezinha, RS, 2014

\begin{tabular}{|c|c|c|c|}
\hline NUTRIENTES & $\begin{array}{c}\text { BERÇÁRIO } \\
\text { (7-11 MESES) } \\
70 \% \text { NND }\end{array}$ & $\begin{array}{c}\text { MATERNAL } \\
\text { (1-3 ANOS) } \\
70 \% \text { NND }\end{array}$ & $\begin{array}{c}\text { PRÉ-ESCOLA } \\
\text { (4-5 ANOS) } \\
20 \% \text { NND }\end{array}$ \\
\hline Calorias (Kcal) & $450^{1}$ & $700^{1}$ & $270^{1}$ \\
\hline VALOR OFERTADO & $+40,27$ & $+28,50$ & $-31,29$ \\
\hline Carboidrato (g) & $73,1^{1}$ & $114,9^{1}$ & $43,9^{1}$ \\
\hline VALOR OFERTADO & $+42,54$ & $+33,17$ & $-31,63$ \\
\hline Proteína (g) & $14^{1}$ & $21,9^{1}$ & $8,4^{1}$ \\
\hline VALOR OFERTADO & $+107,78$ & $+74,47$ & $+33,86$ \\
\hline Lipídio (g) & $11,3^{1}$ & $17,5^{1}$ & $6,8^{1}$ \\
\hline VALOR OFERTADO & $+34,91$ & $+30,38$ & $-2,59$ \\
\hline Fibra (g) & - & $13,3^{1}$ & $5,0^{1}$ \\
\hline VALOR OFERTADO & - & $+20,05$ & $-28,29$ \\
\hline Vitamina A (ug) & $350^{1}$ & $210^{1}$ & $80^{1}$ \\
\hline VALOR OFERTADO & $-57,37$ & $-41,12$ & $-49,25$ \\
\hline Vitamina C (mg) & $35^{1}$ & $12^{1}$ & $5,0^{1}$ \\
\hline VALOR OFERTADO & $+107,41$ & $+440,70$ & $+129,36$ \\
\hline Sódio (mg) & $370^{1}$ & $400^{1}$ & $480^{1}$ \\
\hline VALOR OFERTADO & $-5,97$ & $+88,94$ & $-63,92$ \\
\hline Cálcio (mg) & $189^{1}$ & $350^{1}$ & $160^{1}$ \\
\hline VALOR OFERTADO & $+10,03$ & $-19,95$ & $-88,95$ \\
\hline Ferro (mg) & $7,7^{1}$ & $4,9^{1}$ & $2,0^{1}$ \\
\hline VALOR OFERTADO & $+0,65$ & $+121,72$ & $+79,31$ \\
\hline Magnésio (mg) & $54^{1}$ & $56^{1}$ & $26^{1}$ \\
\hline VALOR OFERTADO & $+42,83$ & $+89,26$ & $-19,48$ \\
\hline Zinco (mg) & $2,1^{1}$ & $2,1^{1}$ & $1,0^{1}$ \\
\hline VALOR OFERTADO & $+69,48$ & $+60,85$ & $-16,46$ \\
\hline
\end{tabular}

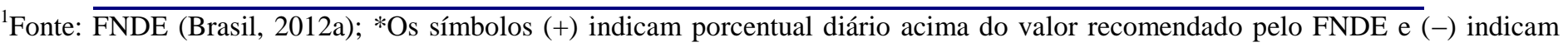
porcentual diário abaixo do valor recomendado pelo FNDE. 
O porcentual mínimo que deve ser atingido com a ingesta de alimentos ofertados segundo o FNDE é de $20 \%$ das necessidades nutricionais diárias (NND) para pré-escolares, por ser ofertada uma refeição diária e pela permanência em período parcial do aluno na escola. Para o berçário e maternal, o porcentual mínimo deve ser de $70 \%$ das necessidades nutricionais diárias, pois permanecem em período integral na escola recebendo, assim, cinco refeições diárias (BRASIL, 2009).

Analisando os dados do berçário, na Tabela 6 observa-se que a alimentação ofertada pela escola está próxima aos $80 \%$ de adequação em relação aos nutrientes e calorias, ficando abaixo apenas na quantidade de vitamina $\mathrm{A}$ e sódio. No maternal, identificou-se o mesmo porcentual, mas com valores abaixo na quantidade de vitamina A e cálcio. Já a pré-escola apresentou $75 \%$ das necessidades nutricionais abaixo do recomendado pelo FNDE (BRASIL, 2009), permanecendo acima apenas em proteína, vitamina C e ferro.

Este fator pode estar associado com a menor quantidade de alimentos ofertados e pelo descumprimento do cardápio estipulado pela nutricionista para a pré-escola, pois as crianças recebiam as mesmas refeições do cardápio ofertado ao maternal. Sendo assim, é muito importante que os manipuladores de alimentos sigam as normas e cardápios estabelecidos pelo nutricionista para que as necessidades nutricionais sejam alcançadas.

Como mostra a Tabela 6, os valores da vitamina A para as três faixas etárias permaneceram entre $41,12 \%$ e $57,37 \%$ abaixo do valor preconizado pelo FNDE, o que foi preocupante pelo fato de a vitamina A ser um micronutriente essencial nessa faixa etária (BRASIL, 2009). Estudos já demonstram que esta deficiência está associada com a morbimortalidade infantil, diarreia e xeroftalmia (SOMMER, 1998).

Como forma de reduzir e controlar essa deficiência nutricional, o Ministério da Saúde instituiu por meio da Portaria n $^{\circ}$ 729, de 13 de maio de 2013, o Programa Nacional de Suplementação de Vitamina A, que consiste na suplementação profilática medicamentosa para crianças de 6 a 59 meses de idade e mulheres no pós-parto, como forma de prevenir a deficiência dessa vitamina no organismo (BRASIL, 2013).

\section{DISCUSSÃO}

Segundo Vaz (2006), para os parâmetros de resto ingesta considera-se como aceitável valores entre $2 \%$ a $5 \%$ da quantidade servida ou de 15 a 45 gramas por pessoa. Vieira e Japur (2012) consideram 0\% a 5\% ótimo e valores maiores que $15 \%$ péssimo. Em nossa pesquisa, o porcentual de resto ingesta diário para o maternal e pré-escola variou de 16,4\% a 33,3\% (Tabela 4), valores considerados elevados quando comparados ao encontrado pelos autores supracitados. Quanto às sobras, tem-se como parâmetro aceitável valores porcentuais de até 3\% ou de 7 a 25 g por pessoa. Em nossa pesquisa, o porcentual de sobra diário para o maternal e pré-escola variou de $10 \%$ a 41,8\%, também considerados elevados quando comparados ao reportado por Vaz (2006).

No berçário os valores diários encontrados para o resto ingesta variaram de 5,9\% a 28,6\%, conforme observado na Tabela 5, valores estes também elevados quando comparados aos citados por Vaz (2006). Para as sobras, os valores diários permaneceram entre $11,6 \%$ a $37,6 \%$.

Para Vaz (2011), os valores elevados de resto ingesta e sobras (alimento produzido e que não foi distribuído) podem demonstrar, por exemplo, a má aceitação da alimentação pelas crianças, repetição do cardápio, qualidade da preparação, porcionamento inadequado e temperatura do alimento. Além disso, foi observada uma produção de alimentos, além da quantidade estipulada para o almoço, para servir no jantar das crianças, ocasionando sobras. 
É importante avaliar o trabalho que está sendo desenvolvido e planejar o adequado número de refeições, o rendimento do alimento e usufruir de alimentos conforme a safra, além de planejar treinamentos com manipuladores, controlar as sobras e, quando possível, manter a apresentação dos pratos de forma agradável e apetitosa. Esses valores também nos mostram que a padronização de técnicas de cocção, porcionamento e o cálculo per capita, são muito importantes para se evitar o desperdício de alimentos e, consequentemente, maior gasto público, pois o alto porcentual de sobras influencia no fator econômico.

Vaz (2011) também defende que os alimentos que permanecem no balcão devem ser considerados resto em razão da sua exposição e risco de contaminação por meio da manipulação, do ambiente, da temperatura e dos próprios usuários do local, e devem ser descartados.

Outros fatores também foram observados durante a pesquisa e podem estar associados com o grande porcentual de resto ingesta. $\mathrm{O}$ almoço começava a ser servido às 10 horas e 30 minutos e as crianças chegavam à escola a partir das 7 horas e 30 minutos da manhã. Neste curto período recebiam o café da manhã e o lanche, ficando saciadas e sem apetite para o almoço. Além disso, observou-se um grande consumo de leite de vaca integral pelos alunos, pois, quando a criança não almoçava, ela recebia uma porção de leite.

Sendo assim, o consumo do leite teve grande influência nos índices de resto ingesta desta pesquisa. No dia em que mais houve perdas de alimentos, as crianças do maternal receberam 11 litros de leite em meio turno. A troca da refeição pelo consumo de leite é um fator preocupante, pois estudos já demonstraram que o consumo de leite de vaca integral constitui um fator de risco para o desenvolvimento de anemia ferropriva em crianças (OLIVEIRA; OSÓRIO, 2005), principalmente quando há substituição de uma alimentação equilibrada pelo mesmo.

A pesquisa realizada por Andrade e Campos (2012) em uma creche mostrou valores de resto ingesta semelhantes aos encontrados em nossa pesquisa, sendo mais elevados do que o ideal. Após o processo de padronização do porcionamento, entretanto, estes porcentuais reduziram aproximadamente pela metade, o que nos mostra, mais uma vez, a necessidade da padronização e de treinamento para diminuir o desperdício de alimentos.

Um estudo conduzido por Neitzke, Molina e Salaroli (2012) sobre alimentação escolar oferecida aos alunos do Ensino Fundamental de um município rural do Estado do Espírito Santo/Brasil, observou que apenas a quantidade de fibras, cálcio e zinco permaneceu abaixo do recomendado pelo FNDE, e os demais macro e micronutrientes ficaram acima do recomendado. Esse resultado foi semelhante ao encontrado em nosso estudo.

O FNDE transfere recursos exclusivamente para compra de gêneros alimentícios para a alimentação escolar (BRASIL, 2010a). Os valores repassados pelo FNDE são calculados com base no número de alunos atendidos, valor per capita e número de dias de atendimento (número de alunos atendidos $\times$ valor per capita $\times$ número de dias de atendimento $=$ Total de recursos repassados $)$.

O número de alunos é fornecido pelo censo escolar do ano anterior. O valor per capita é a quantia estipulada pelo governo, por aluno, para custear a merenda escolar. Atualmente é R \$ 0,50 para alunos matriculados na préescola e em Atendimento Educacional Especializado em contraturno; em escolas indígenas e quilombolas de R $\$$ 0,60, alunos do Programa Mais Educação de $\mathrm{R}$ \$ 0,90 e de $\mathrm{R}$ \$ 1,00 para alunos matriculados em creches e em ensino integral. O número de dias de atendimento, a ser considerado nos cálculos, é de 200 dias letivos por ano (BRASIL, 2009, 2010b). 
Diante do exposto e conforme preconizado pelo PNAE, a merenda deve oferecer, pelo menos, três porções de frutas e hortaliças por semana. Os cardápios analisados nesta pesquisa cumprem com a oferta de, no mínimo, três porções de frutas semanais. Além de oferecer produtos naturais, a prefeitura deve gastar a maior parte do dinheiro do programa com produtos básicos, como arroz, feijão, açúcar e farinha de trigo. As refeições devem ser preparadas nas escolas, tendo por objetivo evitar os doces, os refrigerantes, os "alimentos formulados", como sopas e risotos semiprontos, os enlatados e os alimentos concentrados (em pó ou desidratados para reconstituição) (BRASIL, 2012a).

De acordo com o Tribunal de Contas da União, a prefeitura deve gastar, no máximo, 30\% dos recursos com esses produtos (BRASIL, 2010b). Esses alimentos são fáceis de preparar, mas não muito saudáveis e são sempre mais caros. Vale lembrar que é proibida a compra de refrigerantes e refrescos artificiais com os recursos da merenda escolar. Isso vai contra o que observamos atualmente nas escolas, que, no lugar de refeições nutricionalmente adequadas, fornecem às crianças pequenos lanches fora dos padrões estabelecidos pelo programa e com valores energéticos abaixo do preconizado para determinada faixa etária.

Para Proença et al. (2008), o cardápio elaborado por um nutricionista, principalmente para crianças, pode ser utilizado na educação nutricional para prevenir ou melhorar o estado de saúde, sempre levando em conta que, se não elaborado com certo cuidado, pode fragilizar o estado de saúde das crianças, além de que o cardápio influencia na formação de hábitos alimentares, principalmente na infância.

Além disso, a prefeitura também deve procurar saber se existe boa aceitação da merenda. O ideal é que seja feita pesquisa junto aos alunos sobre a preferência alimentar dos mesmos. Essa informação deve ser usada para dar prioridade aos produtos mais bem aceitos nas próximas compras, dentro do possível e desde que sejam saudáveis. Dessa forma, estará respeitando os hábitos alimentares da região.

\section{CONCLUSÃO}

O desenvolvimento de um programa de promoção de hábitos saudáveis, envolvendo a família e a comunidade escolar, a capacitação e a sensibilização dos profissionais envolvidos na produção de alimentos na escola, bem como o compromisso público no investimento adequado das verbas destinadas à merenda escolar, são ações primordiais na prevenção e no controle dos distúrbios nutricionais nessa faixa etária.

Observou-se que a inadequação nutricional dos cardápios propostos pode ser justificada pelo planejamento incorreto, tanto do ponto de vista dos ingredientes escolhidos quanto pelo dimensionamento das quantidades per capita e ausência de fichas técnicas e treinamento dos manipuladores.

Adicionalmente, o desajuste de alguns índices avaliadores da produção e distribuição das refeições aponta para a necessidade de medidas corretivas, a fim de reduzir gastos desnecessários. Assim, reforça-se a importância do acompanhamento, pelo profissional qualificado, na elaboração do cardápio e no preparo e distribuição dos alimentos, visando a garantir a adequação da alimentação oferecida em termos qualitativos e quantitativos.

Por fim, é importante que os colaboradores tenham o compromisso de preparar o alimento proposto pelo responsável técnico para evitar desequilíbrios nutricionais na alimentação ofertada. A elaboração do cardápio deve ser realizada cautelosamente para que todos os nutrientes sejam alcançados e para que as refeições não se tornem monótonas. 


\section{REFERÊNCIAS}

ABREU, E. S.; SPINELLI, M. G. N.; ZANARDI, A. M. P. Gestão de unidades de alimentação e nutrição: um modo de fazer. São Paulo: Editora Metha, 2003.

ANDRADE, J. C.; CAMPOS, F. M. Porcionamento, adequação energética e controle do desperdício em uma creche. Demetra, Rio de Janeiro, v. 7, n. 3, p. 157-180, 2012.

BRASIL. Ministério da Educação. Resolução/CD/FNDE $n^{\circ}$ 38, de 16 de julho de 2009. Dispõe sobre o atendimento da alimentação escolar aos alunos da educação básica no Programa Nacional de Alimentação Escolar (PNAE). Brasília, 2009. Disponível em: <https://www.fnde.gov.br/fndelegis/action/UrlPublicasAction.php?acao=abrirAtoPublico\&sgl_tipo=RES\&num_ato=00000038\&seq_ ato=000\&vlr_ano=2009\&sgl_orgao=CD/FNDE/MEC $>$. Acesso em: 20 jun. 2016.

. Ministério da Saúde. Secretaria de Atenção à Saúde. Dez passos para uma alimentação saudável: guia alimentar para crianças menores de dois anos: um guia para o profissional da saúde na atenção básica. 2. ed. Brasília, 2010a. Disponível em: <http://bvsms.saude.gov.br/bvs/publicacoes/10_passos.pdf >. Acesso em: 20 jun. 2016.

. Tribunal de Contas da União (TCU). Cartilha para Conselheiros do Programa Nacional de Alimentação Escolar (PNAE). 5. ed. Brasília, 2010b. Disponível em: <http://portal.tcu.gov.br/lumis/portal/file/fileDownload.jsp?fileId=8A8182A24D6E86A4014D72AC812A5383\&inline=1>. Acesso em: 20 jun. 2016.

. Ministério da Educação. Fundo Nacional de Desenvolvimento Escolar (FNDE). Resolução $n^{\circ}$ 8, de 14 de maio de 2012. Altera os valores per capita da educação infantil no âmbito do Programa Nacional de Alimentação Escolar (PNAE). Brasília, 2012 a. Disponível <https://www.fnde.gov.br/fndelegis/action/UrlPublicasAction.php?acao=abrirAtoPublico\&sgl_tipo=RES\&num_ato=00000008\&seq ato $=000 \& v 1 r \_a n o=2012 \& s g l \_o r g a o=C D / F N D E / M E C>$. Acesso em: 20 jun. 2016.

. Ministério da Educação. Manual de orientação para a alimentação escolar na educação infantil, ensino fundamental, ensino médio e na educação de jovens e adultos. Org. Francisco de Assis Guedes de Vasconcelos et al. 2. ed. Brasília: PNAE; CECANE-SC, 2012b. Disponível em: <manual_etapas_ensino_-_2ed.pdf>. Acesso em: 20 jun. 2016.

. Ministério da Saúde. Secretaria de Atenção à Saúde. Departamento de Atenção Básica. Manual de condutas gerais do Programa Nacional de Suplementação de Vitamina A. Brasília, 2013. Disponível em: <http://bvsms.saude.gov.br/bvs/publicacoes/manual_condutas_suplementacao_vitamina_a.pdf>. Acesso em: 20 jun. 2016.

COLARES, L. G. T.; FREITAS, C. M. Processo de trabalho e saúde de trabalhadores de uma unidade de alimentação e nutrição: entre a prescrição e o real do trabalho. Cad. Saúde Pública, São Paulo, v. 23, n. 12, p. 3.011-3.020, 2007.

FUNDO DAS NAÇÕES UNIDAS PARA A INFÂNCIA. Unicef. Declaração dos direitos da criança (1959). Disponível em: <http://www.unicef.org/brazil/decl_dir.htm>. Acesso em: 20 jun. 2016.

INSTITUTO BRASILEIRO DE GEOGRAFIA E ESTATÍSTICA. IBGE. Informações completas: Arvorezinha. Disponível em: <http://www.cidades.ibge.gov.br/xtras/perfil.php?lang=\&codmun=430140\&search=rio-grande-do-sul|arvorezinha|infograficos:informacoes-completas>. Acesso em: 20 jun. 2016.

NEITZKE, L.; MOLINA, M. de C. B.; SALAROLI, L. B. Nutritional adequacy of school feeding in rural municipality - Espírito Santo, Brazil. Rev Nutrire, São Paulo, v. 37, n. 1, p. 1-12, 2012.

OLIVEIRA, M. A. A.; OSÓRIO, M. M. Cow's milk consumption and iron deficiency anemia in children. J. Pediatria, Rio de Janeiro, v. 81, n. 5, p. 361-367, 2005.

PINHEIRO, A. B. V. et al. Tabela para avaliação de consumo alimentar em medidas caseiras. 5. ed. São Paulo: Atheneu, 2008. 
PROENÇA, R. P da C. et al. Qualidade nutricional e sensorial na produção de refeições. 3. ed. Florianópolis: UFSC, 2008.

SOCIEDADE BRASILEIRA DE PEDIATRIA. Manual de orientação: alimentação do lactente, alimentação do pré-escolar, alimentação do escolar, alimentação do adolescente, alimentação na escola. São Paulo, 2006. Disponível em: <https://www.sbp.com.br/img/manuais/manual_alim_dc_nutrologia.pdf〉. Acesso em: 20 jun. 2016.

SOMMER, A. Xerophthalmia and vitamin A status. Prog Retin Eye Res, v. 17, n. 1, p. 9-31, 1998.

TABELA BRASILEIRA DE COMPOSIÇÃO DE ALIMENTOS (TACO/NEPA). 4. ed. rev. e ampl. Campinas: Unicamp, 2011. Disponível em: 〈http://www.unicamp.br/nepa/taco/contar/taco_4_edicao_ampliada_e_revisada〉. Acesso em: 20 jun. 2016.

VAZ, C. S. Restaurantes: controlando custos e aumentando lucros. Brasília: LGE, 2006. Alimentação de coletividade: uma abordagem gerencial. Brasília: Metha, 2011.

VIEIRA, M. N. C. M.; JAPUR, C. C. Gestão de qualidade na produção de refeições. Rio de Janeiro: Guanabara Koogan, 2012. 